\title{
Characters of Rachis and Grain within Different Spike Parts in Spike Hetero Branching Wheat (Triticum aestivum L.)
}

\author{
Lanfei Zhao ${ }^{1}$, Weidong Zhang ${ }^{1}$, Qingrong Gao ${ }^{1}$, Anfei $\mathrm{Li}^{1} \& \mathrm{Jich} \mathrm{Tian}^{1}$ \\ ${ }^{1}$ Genetic Breeding Department, Agronomy College, State Key Laboratory of Crop Biology, Shandong \\ Agricultural University, Shandong Province, P. R. China \\ Correspondence: Weidong Zhang, Genetic Breeding Department, Agronomy College, State Key Laboratory of \\ Crop Biology, Shandong Agricultural University, Shandong Province, P. R. China. Tel: 86-538-824-8501, E-mail: \\ zhangwd@sdau.edu.cn \\ Qingrong Gao, Genetic Breeding Department, Agronomy College, State Key Laboratory of Crop Biology, \\ Shandong Agricultural University, Shandong Province, P. R. China. Tel: 86-538-824-8501, E-mail: \\ gaoqingr@sdau.edu.cn
}

Received: August 30, 2012 Accepted: September 24, 2012 Online Published: November 15, 2012

doi:10.5539/jas.v4n12p106 URL: http://dx.doi.org/10.5539/jas.v4n12p106

This research is supported by Key Program for Natural Sciences Fund in Shandong Province (ZR2012CZ001)

This research is supported by Wheat Breeding and Demonstration for high and stable yield, high quality in Henan Grain Core Area supported by Ministry of science and technology in China (2011BAD07B01)

This research is supported by Special Program from Ministry of science and technology in China (2011ZX08002-003)

\begin{abstract}
Spike hetero branching wheat (Triticum aestivum) (SHBW) has one main rachis, but has branched rachises at lower parts of main rachis. This type of spike could increase greatly grain number by bearing grain in branching rachis. In this study, field experiments were conducted at three locations in Huanghuai wheat zone during two growing seasons (2008-2010). The rachises length, node number, grain number, and grain weight were investigated within five different spikes parts. The results showed that the proportion of the length of upper no-branching part to that of lower branching part within the main rachis varied from 0.49-0.99; The coefficient of variations (CVs) of main rachis length, node number within main rachis and grain number and thousand grain weight within the upper part of main rachis were $9.78 \%, 8.49 \%, 21.73 \%$ and $17.32 \%$, respectively, but CVs of these traits within the branched rachises were $54.45 \%, 37.21 \%, 36.80 \%$, and $19.45 \%$, respectively. This indicated that the morphological characters within branched rachises were more easily influenced by external environments. Grain number in the whole spike and average branched rachises length were unstable under various environments and the two traits should be regarded as the main choice factors in future breeding selection in SHBW.
\end{abstract}

Keywords: branched wheat, spike morphology, rachis, grain set, grain weight

\section{Introduction}

In normal common wheat a rachis is the main axis of the inflorescence or spike. Generally, a ripe spike of wheat only has a main rachis, and spikelets are borne on rachis node. Spikelets are small inflorescences bearing one or more florets, or small flowers, along with a set of miniature bractlike leaves.

Spike Hetero Branching Wheat (Triticum aestivum) (SHBW) has an abnormal spike morphology expressing branchiness of the turgidum type which was incorporated in T. aestivum using wide crosses between T. aestivum and branching forms of Triticum turgidum (Koric, 1980; Dencic, 1988; Huang et al., 1988).

SHBW has a main rachis as normal common wheat, but displays two different spike morphotypes in a spike (Figure 1). Generally, the upper part of the main rachis presents standard spike morphotype, and bear one spikelet per rachis node; The low part of the main rachis presents branching spike morphotype, in other words, it bear a branching rachis at each main rachis node. Spikelets are borne on branching rachis node and thus might offer more possibility for more florets in a spike. 
The genetics of this supernumerary spikelet in wheat has been studies for over ninety years. In T. turgidum, this character was found to be inherited in a recessive manner (Tschermak, 1914; Sharman, 1967). The inheritance of branched rachises in common wheat was found to be controlled by two recessive genes with evidence for the possibility of a repressor(s) in crosses between normal and SHBW lines (Koric, 1980). At the same time it was also affected by light, temperature, nutrients and environmental conditions (Koric, 1975; Peanel1, 1983). Environmental factors played a minor effect on the expression of supernumerary spikelet character during spike differentiation stage at the same eco-region (Sun et al., 2000).

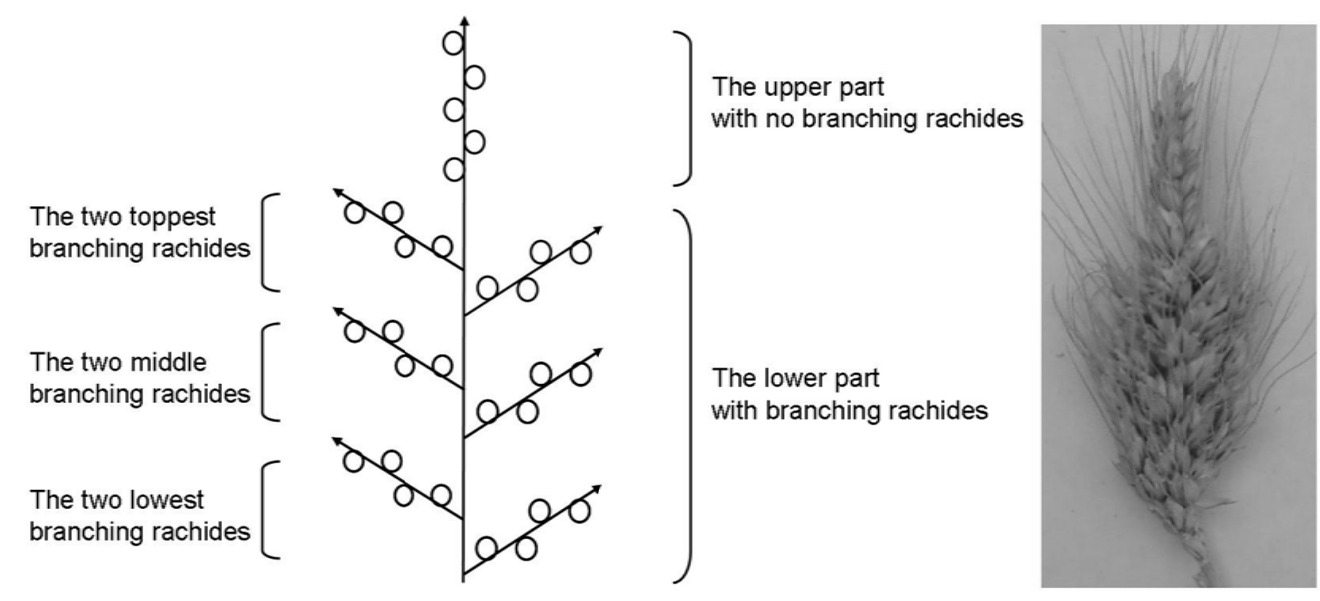

Figure 1. Schematic diagram indicating the different spike parts in SHBW. The arrows represent the main rachis or branched rachises and the circle represents spikelet on rachis

However, there were some different research results in this kind of branched rachises inheritance. Chromosomal location of the genes for the branched rachises character in the bread wheat line, Yupi Branching was determined by monosomic analysis, and the results indicated that chromosome 2D, 4A, 4B and 5A of bread wheat carry genes for branched rachises character. Among them, the gene on chromosome 2D has the strongest effect on the expression of the branched rachises character (Peng et al., 1998).

The main components of wheat yield are the spike number per unit land area, the number of grains per spike, and the average weight of those grains. Normal common wheat spikes bear one spikelet per rachis node, and the formation of supernumerary spikelets is rare. SHBW with branched rachises could bear supernumerary spikelet or much more grain in a spike and thus increases greatly grain number in one spike.

About twenty years ago (1993), Fen33, a SHBW cultivar was released to be cultivated in some northern western China wheat zones. Fen 33 with branched rachises has been selected from interspecies hybridization of $T$. turgidum $\times$ T. aestivum. Branched spike character was derived from T. turgidum (Yuan et al., 1995). It was also proved that branched spike character in Fen33 is controlled by two recessive genes and maybe affected by some modifying genes (Zhao et al., 2009).

However, Fen33 could not be planted in larger areas and it disappeared soon in production area. This kind of SHBW was not released in China wheat production in later years. It is said that the failure application of the kind of wheat in practice might be due to its unstable grain yield.

Characters of a spike should be the first component in influencing the wheat yield. Grain weight and mumber varied with different positions within the spike in normal wheat (Slafer et al., 1994; Acreche et al., 2006). It is necessary to determine if the branchiness displays a wide range of different levels in various environments. Using a SHBW elite line SG203 as material, a field study was conducted at three locations in Huanghuai wheat zone in China during two growing seasons (2008-2009 and 2009-2010) to determine the characters of rachis and grain, including rachis length, rachises node number, grain set and grain weight within different spike parts. This research might lay foundation for utilizing this kind of supernumerary grain germplasm in wheat breeding. 


\section{Materials and methods}

\subsection{Plant Materials}

A SHBW elite line SG203, which was an offspring from Fen33 crossed with Weimai, a most common wheat cultivar in Huanghuai wheat zone in China, was adopted in these trials because it is more suitable to grow in the Huanghuan wheat zone than one of its parents, Fen33. Fen33 was a registered cultivar which was examined and approved in 1993 and was recommended in the Northern wheat growing zone from then. However, Fen 33 has not been planted extensively in wheat production afterwards.

\subsection{Study Sites}

Experiments were conducted at three locations in Huanghuai wheat zone in Taian $\left(36^{\circ} 11^{\prime} \mathrm{N}, 117^{\circ} 8^{\prime} \mathrm{E}\right.$ and $135 \mathrm{~m}$ a.s.l), Cangzhou ( $38^{\circ} 20^{\prime} \mathrm{N}, 116^{\circ} 50^{\prime} \mathrm{E}$ and $34 \mathrm{~m}$ a.s.l) and Jiyuan $\left(35^{\circ} 5^{\prime} \mathrm{N}, 112^{\circ} 34^{\prime} \mathrm{E}\right.$ and $267 \mathrm{~m}$ a.s.l), in Eastern China, during two growing seasons (2008-2009 and 2009-2010). At Taian, the study was part of a long-term breeding experiment started in 1998 and conducted at the Experimental Farm for Cereal Research in Shandong Agricultural University on a clay-silty loamy soil. At Cangzhou, the study was conducted at the Experimental Station for Crop Breeding on clay loamy soil with minor salt content $(0.21 \%)$. At Jiyuan, the study was conducted at the Experimental Station in silty clay-loamy soil in Jiyuan Crop Institute. Soil characteristics of three locations are reported in Table 1.

Table 1. Physicochemical properties of the soil at the three wheat cultivation locations

\begin{tabular}{llll}
\hline Characteristics & Taian & Cangzhou & Jiyuan \\
\hline $\mathrm{pH}\left(1: 2.5 \mathrm{H}_{2} \mathrm{O}\right)$ & 7.83 & 8.24 & 7.95 \\
Clay $(\%)$ & 28.5 & 41.7 & 38.5 \\
Silt (\%) & 52.3 & 51.9 & 15.5 \\
Sand (\%) & 19.5 & 6.4 & 46.3 \\
Organic carbon (\%) & 0.685 & 0.543 & 0.874 \\
Inorganic C & 0.635 & 0.632 & 0.796 \\
Organic matter (\%) & 1.45 & 2.78 & 3.58 \\
Total nitrogen (\%) & 0.26 & 0.14 & 0.15 \\
Total phosphorus (\%) & 0.036 & 0.045 & 0.056 \\
Total potassium (\%) & 0.14 & 0.28 & 0.21 \\
Bulk density $\left(\mathrm{Mg} \mathrm{m}^{-3}\right)$ & 1.23 & 1.36 & 1.25 \\
Salt content & - & $0.21 \%$ & - \\
\hline
\end{tabular}

In each location, wheat was planted in 4 replicates with plot of $1.5 \mathrm{~m} \times 6 \mathrm{~m}\left(9 \mathrm{~m}^{2}\right)$ in this study. Two hundred seedlings were planted per square meter at equal spacing. Irrigation was applied when necessary throughout the growing season in Taian and Cangzhou. In Jiyuan, the irrigation during the reproductive period was not enough as in the two other locations because the growth site located in a hilly area. In order to ensure consistent fertilization among the three locations, nitrogen $\left(30 \mathrm{~kg} \mathrm{~N} \mathrm{ha}^{-1}\right)$ was only applied before sowing (incorporated by disk harrowing) as ammonium phosphate, and no $\mathrm{N}$ top-dressed applied at the beginning of wheat tillering. All other cultural practices, such as weed, insect and disease control, were standard and uniform according to the local farmer cultivation practices.

\subsection{Spike Data Collection}

Five hundreds of representative mature wheat spikes in main stem were randomly sampled in each replicate at the end of the wheat growing season.

SG203 spikes were divided into five subsamples according to the different portions in a spike (Figure 1). The main rachis falls into two parts, no-branching part and branching part. No-branching part, or the upper part of the main rachis had a spikelet at a main rachis node; branching part, or the lower part of main rachis had a branching rachis at a rachis node. The branched rachises within the lower part of the main rachis fall into another three parts according to their relative positions along the main rachis. The three parts data were collected by sampling the two toppest branched rachises, the two lowest branched rachises and the two branched rachises in the middle of main rachis respectively. 
In each replicate, rachis length, node number or grain number were measured by taking samples consisting of no less than 30 spikes from main stem. Each sample was measured with scale from the base of the rachis to the apex to record the rachis length in $\mathrm{cm}$. Number of rachis node was counted. To record the grains per rachis, each spike was threshed separately and grains of each rachis were counted and averaged. The grain samples were dried at $60{ }^{\circ} \mathrm{C}$ for $48 \mathrm{~h}$ before weight measured. No less than 500 grains within different spike parts were counted at random and were weighed in an electronic scientific balance.

\subsection{Statistical Analysis}

All experimental data were subjected to analysis using SPSS, version 19.0 (SPSS, 2010). Mean values were compared by the LSD method or Duncan's multiple range test at the 5\% level.

\section{Results and Discussion}

\subsection{Weather Conditions}

All the three wheat growth locations belong to the Huang Huai wheat zone, and their climate conditions are roughly consistent. Weather conditions are summarized in Table 2. Generally, vegetative growth of SG203 in this zone occurred from October to the end of February and the reproductive period (stem elongation, heading, grainfilling, and maturation) occurred from March to June in each growing season. As typical temperate climate, quantity and distribution of rain fall were highly variable, and it rains sparsely in winter and early spring (from November to February). Rainfall (October-June) varied among the 2 years (Table 2), with ranges from 227.7 to $273.8 \mathrm{~mm}$ at Taian, from 211.3 to $267.6 \mathrm{~mm}$ at Cangzhou, and 215.9 to 239.9 at Jiyuan. Although the yearly rainfall in Jiyuan was not less than those in two other experimental locations, the irrigation was poor and not enough as in the two other places during the reproductive period. During the all growth period (October-June), temperatures varied widely for each location and study-year. Mean temperature at Taian and Cangzhou were $8.97^{\circ} \mathrm{C}$ and $9.96^{\circ} \mathrm{C}$ respectively which were always lower than that at Jiyuan $\left(12.14^{\circ} \mathrm{C}\right)$.

Table 2. Monthly rainfall and mean maximum and minimum temperature for two growing seasons (2008-2010) in Taian, Cangzhou and Jiyuan, Huanghuai Wheat zone, China

\begin{tabular}{|c|c|c|c|c|c|c|c|c|c|c|}
\hline & & \multicolumn{3}{|c|}{ Taian } & \multicolumn{3}{|c|}{ Cangzhou } & \multicolumn{3}{|c|}{ Jiyuan } \\
\hline & & $\begin{array}{c}\text { Tmax } \\
\left({ }^{\circ} \mathrm{C}\right)\end{array}$ & $\begin{array}{l}\text { Tmin } \\
\left({ }^{\circ} \mathrm{C}\right)\end{array}$ & $\begin{array}{c}\text { Rainfall } \\
(\mathrm{mm})\end{array}$ & $\begin{array}{l}\text { Tmax } \\
\left({ }^{\circ} \mathrm{C}\right)\end{array}$ & $\begin{array}{l}\text { Tmin } \\
\left({ }^{\circ} \mathrm{C}\right)\end{array}$ & $\begin{array}{c}\text { Rainfall } \\
(\mathrm{mm})\end{array}$ & $\begin{array}{l}\text { Tmax } \\
\left({ }^{\circ} \mathrm{C}\right)\end{array}$ & $\begin{array}{l}\text { Tmin } \\
\left({ }^{\circ} \mathrm{C}\right)\end{array}$ & $\begin{array}{c}\text { Rainfall } \\
(\mathrm{mm})\end{array}$ \\
\hline \multirow{9}{*}{$\begin{array}{c}2008 \\
- \\
2009\end{array}$} & Oct. & 28.8 & -3.20 & 39.2 & 17.5 & 9.6 & 23.6 & 32.5 & -0.2 & 37.8 \\
\hline & Nov. & 24.5 & -10.6 & 13.5 & 12.3 & 2.3 & 10.2 & 24.6 & -5.8 & 15.6 \\
\hline & Dec. & 15.3 & -17.5 & 9.4 & 5.4 & -3.5 & 5.3 & 21.3 & -7.9 & 9.6 \\
\hline & Jan. & 14.2 & -19.8 & 6.3 & 2.3 & -9.8 & 3.4 & 20.6 & -12.3 & 8.4 \\
\hline & Feb. & 18.6 & -16.3 & 7.4 & 8.7 & -6.5 & 7.5 & 21.3 & -13.6 & 13.6 \\
\hline & Mar. & 24.3 & -10.7 & 12.3 & 11.9 & -0.5 & 17.9 & 27.8 & -6.5 & 14.6 \\
\hline & $\begin{array}{c}\text { Apri } \\
1\end{array}$ & 27.2 & -4.12 & 24.3 & 21.4 & 9.7 & 25.6 & 32.6 & 2.3 & 25.6 \\
\hline & May & 34.5 & 2.6 & 27.7 & 25.7 & 14.7 & 45.3 & 38.5 & 6.8 & 31.8 \\
\hline & June & 37.8 & 10.9 & 87.6 & 29.8 & 19.8 & 72.5 & 40.1 & 12.9 & 58.9 \\
\hline \multirow{9}{*}{$\begin{array}{c}2009 \\
- \\
2010\end{array}$} & Oct. & 30.2 & -2.4 & 26.4 & 18.6 & 11.2 & 35.3 & 28.9 & -2.44 & 28.6 \\
\hline & Nov. & 26.2 & -9.8 & 15.9 & 9.8 & 3.1 & 17.8 & 23.6 & -7.04 & 12.8 \\
\hline & Dec. & 14.4 & -16.7 & 13.6 & 3.5 & -2.9 & 12.3 & 21.6 & -9.14 & 9.4 \\
\hline & Jan. & 12.9 & -15.0 & 12.7 & -1.4 & -5.4 & 5.6 & 17.4 & -15.5 & 6.5 \\
\hline & Feb. & 17.2 & -17.5 & 15.9 & 8.9 & 1.2 & 10.9 & 21.6 & -14.8 & 12.3 \\
\hline & Mar. & 21.3 & -3.9 & 21.3 & 14 & -0.9 & 23.4 & 25.9 & -7.7 & 24.6 \\
\hline & Apr. & 25.1 & -0.3 & 32.6 & 17.6 & 10.2 & 31.5 & 30.9 & 5.0 & 32.8 \\
\hline & May & 31.4 & 1.3 & 39.8 & 26.7 & 15.8 & 43.2 & 38.1 & 8.5 & 47.1 \\
\hline & June & 34.5 & 12.6 & 95.6 & 28 & 21.3 & 87.6 & 40.2 & 13.6 & 65.8 \\
\hline
\end{tabular}




\subsection{The Length of Main Rachis and Branched Rachises}

Our results showed that two spike morphology displaying in a main rachis is a common characteristic in this SHBW elite, but the proportion of branching main rachis within the main rachis were significantly different under the three growth locations $(\mathrm{P}<0.001)$ (Table 3). The proportion of upper no-branching part to lower branching parts in main rachis varied from 0.49-0.99. The productive potentialities of SHBW lies in the branched rachises with more spikelet or floret, so more proportion of branching main rachis in a spike in this kind of wheat should be beneficial for future utilization.

Table 3. The length of main rachis and branched rachises for two growing seasons (2008-2010) in Taian, Cangzhou and Jiyuan, Huanghuai Wheat zone, China ${ }^{*}$. The data units are $\mathrm{cm}$

\begin{tabular}{|c|c|c|c|c|c|c|c|}
\hline & & \multicolumn{3}{|c|}{ Main rachis } & \multicolumn{3}{|c|}{ Lower part } \\
\hline & & $\begin{array}{l}\text { Upper } \\
\text { part }\end{array}$ & $\begin{array}{l}\text { Lower } \\
\text { part }\end{array}$ & Total & $\begin{array}{l}\text { Toppest branched } \\
\text { rachises }\end{array}$ & $\begin{array}{l}\text { Middle branched } \\
\text { rachises }\end{array}$ & $\begin{array}{c}\text { Lowest branched } \\
\text { rachises }\end{array}$ \\
\hline \multirow[t]{3}{*}{ 2008-2009 } & Taian & $4.92 \pm 0.32$ & $5.26 \pm 0.42$ & $10.18 \pm 0.78$ & $1.44 \pm 0.09$ & $1.86 \pm 0.13$ & $1.33 \pm 0.06$ \\
\hline & Cangzhou & $2.86 \pm 0.19$ & $5.78 \pm 0.59$ & $8.64 \pm 0.86$ & $1.27 \pm 0.12$ & $2.14 \pm 0.19$ & $1.65 \pm 0.09$ \\
\hline & Jiyuan & $2.25 \pm 0.25$ & $5.44 \pm 0.26$ & $7.69 \pm 0.79$ & $0.28 \pm 0.03$ & $0.47 \pm 0.06$ & $0.27 \pm 0.06$ \\
\hline \multirow[t]{3}{*}{$2009-2010$} & Taian & $4.34 \pm 0.35$ & $4.32 \pm 0.33$ & $8.66 \pm 0.89$ & $1.54 \pm 0.11$ & $1.72 \pm 0.15$ & $1.29 \pm 0.08$ \\
\hline & Cangzhou & $4.21 \pm 0.31$ & $6.55 \pm 0.41$ & $10.76 \pm 0.96$ & $0.93 \pm 0.78$ & $1.59 \pm 0.12$ & $0.92 \pm 0.05$ \\
\hline & Jiyuan & $4.17 \pm 0.41$ & $5.68 \pm 0.36$ & $9.85 \pm 0.73$ & $0.36 \pm 0.06$ & $0.54 \pm 0.08$ & $0.38 \pm 0.05$ \\
\hline
\end{tabular}

*, Upper part and lower part indicated that the length of upper main rachis with no branched rachises and lower main rachis with branched rachises respectively; toppest branched rachises, middle branched rachises and lowest branched rachises indicated that the average length of two branched rachises at different positions within the lower part of main rachis; the values were showed as SD; unit, centimeter.

Analysis of variance showed that the main rachis length was significantly different under various environments $(\mathrm{P}<0.001)$. The highest value for rachis length $(10.76 \mathrm{~cm})$ was observed in Cangzhou in 2009-2010 whereas the lowest $(8.64 \mathrm{~cm}$ ) was seen in Jiyuan in 2008-2009 (Table 3). Spike length of a wheat line usually shows some stability under different conditions. The length of rachis in Jiyuan was significantly less than those in Taian and Cangzhou $(\mathrm{P}<0.05)$, and this might be due to the water deficit during the floral initiation to anthesis period (March-May) in Jiyuan. The results of the present study demonstrated that the length of main rachis decreased significantly under lacking sufficient water irrigation, which is congruent with the reports of Iqbal et al. (1999) on durum wheat and Ghodsi (2004) on bread wheat. Main rachis length was not significantly different between Taian and Cangzhou $(\mathrm{P}>0.05)$, and this indicated that a slight salt stress had little effect on main rachis length.

The growth location effect was highly significant on the mean length of branched rachises $(\mathrm{P}<0.001)$ (Table 3$)$. The average length of branched rachises appeared to vary in similar trends with that of the main rachis under various environments, but their variation ranges differed greatly. The coefficient of variation $(\mathrm{CV})$ was $54.45 \%$ for average length of all branched rachises, whereas only $9.78 \%$ for the main rachis among the various environments. The average length of branched rachises in Jiyuan was only $41.71 \%$ and $23.93 \%$ of the lengths of branched rachises in Taian and Cangzhou, respectively. This indicated that the branched rachises length was prone to variation if the environmental conditions changed and the drought might be one important factor in branched rachises length determination. In addition, the length of the middle branched rachises was less affected than those of the lowest or toppest branched rachises by the external environments. Its CV was $51.0 \%$, whereas the CVs of the lowest and toppest branched rachises were $56.2 \%$ and $56.9 \%$ respectively.

\subsection{The Number of Rachis Node on Main Rachis and Branched Rachises}

Many research in the past focused on the spikelet in a spike rather than rachis node. In our study, rachis node substituted spikelet as a morphological trait in a SHBW spike. Spikelet, which bears grain, located at the node site of rachis and spikelet per spike could be regarded as an important trait of spike morphology. Generally, only one spikelet bears at one rachis node in normal wheat. In SHBW's spike, within the upper part of the main rachis, only one spikelet bears at a node, and this is like normal wheat. Within lower part of the main rachis, the branched 
rachises, instead of spikelet, locates at node site. The node number within rachis determinates the grain number, since node site provides the potential location for spikelet, florets or grains bearing.

Our results showed that the node site number of main rachis was significantly different under various environments $(\mathrm{P}<0.01)$, and the interaction effect of location $\times$ year was also highly significant $(\mathrm{P}<0.05)($ Table 4$)$. The highest value for rachis node (21.16) was observed in Taian in 2008-2009 whereas the lowest (16.75) was found in Cangzhou in 2008-2009. Jan et al. (2000) reported that spikelets spike ${ }^{-1}$ in a rachis is an inherent character of a wheat variety, which is slightly influenced by environmental factors. However, Hussain (1984) and Rizwan (2007) observed that increasing nitrogen application resulted in an increase in the number of spikelet per spike. In our study, fertilization might not be the factor influencing the node number, because fertilization were applied equally at the three locations. In addition, our results showed that there was positive correlation between the number of node site within the main rachis and the length of main rachis $(\mathrm{P}<0.05)$, but the $\mathrm{CV}$ of rachis node $(8.49 \%)$ was less than that of main rachis length $(9.78 \%)$. The variance ranges of average node number on different branched rachises were higher than that on main rachis. CVs were $36.92 \%, 28.33 \%$ and $34.74 \%$ for average number of the toppest, middle and lowest two branched rachises, whereas only $8.49 \%$ for the main rachis. The node number on branched rachises in Jiyuan was only $74.10 \%$ and $49.71 \%$ of those in Taian and Cangzhou, respectively. This showed that lack of water could significantly reduce the number of node within branched rachises. As the CVs indicated, the node number within the middle two branched rachises in the lower part of main rachis was also less affected than those within the lowest and toppest branched rachises.

Table 4. The number of rachis node on main rachis and branched rachises for two growing seasons (2008-2010) in Taian, Cangzhou and Jiyuan, Huanghuai Wheat zone, China* The data units are the number of rachis node

\begin{tabular}{|c|c|c|c|c|c|c|c|}
\hline & & \multicolumn{3}{|c|}{ Main rachis } & \multicolumn{3}{|c|}{ Lower part } \\
\hline & & Upper part & Lower part & Total & $\begin{array}{l}\text { Toppest branched } \\
\text { rachises }\end{array}$ & $\begin{array}{l}\text { Middle branched } \\
\text { rachises }\end{array}$ & $\begin{array}{l}\text { Lowest branched } \\
\text { rachises }\end{array}$ \\
\hline \multirow[t]{3}{*}{ 2008-2009 } & Taian & $11.95 \pm 0.93$ & $9.21 \pm 0.89$ & $21.16 \pm 1.56$ & $3.12 \pm 0.32$ & $3.45 \pm 0.41$ & $4.03 \pm 0.32$ \\
\hline & Cangzhou & $8.08 \pm 0.56$ & $8.67 \pm 0.46$ & $16.75 \pm 1.32$ & $3.06 \pm 0.26$ & $3.44 \pm 0.23$ & $4.97 \pm 0.42$ \\
\hline & Jiyuan & $7.11 \pm 0.64$ & $10.23 \pm 0.84$ & $17.34 \pm 0.89$ & $1.22 \pm 0.06$ & $2.2 \pm 0.16$ & $2.01 \pm 0.25$ \\
\hline \multirow[t]{3}{*}{$2009-2010$} & Taian & $10.38 \pm 0.84$ & $9.01 \pm 0.42$ & $19.39 \pm 1.23$ & $3.09 \pm 0.13$ & $3.37 \pm 0.35$ & $5.97 \pm 0.35$ \\
\hline & Cangzhou & $10.03 \pm 0.65$ & $9.12 \pm 0.75$ & $19.15 \pm 0.65$ & $3.73 \pm 0.24$ & $4.09 \pm 0.52$ & $4.48 \pm 0.41$ \\
\hline & Jiyuan & $7.82 \pm 0.45$ & $10.44 \pm 0.95$ & $18.26 \pm 0.96$ & $1.66 \pm 0.23$ & $1.81 \pm 0.06$ & $2.98 \pm 0.19$ \\
\hline
\end{tabular}

*, Upper part and lower part indicated that rachis node number of the upper main rachis with no branched rachises and lower main rachis with branched rachises respectively; toppest branched rachises, middle branched rachises and lowest branched rachises indicated that the average node number of two branched rachises at different positions within the lower part of main rachis; the values were showed as SD.

\subsection{The Grain Number within Different Spike Parts}

Grain number is one of the three components in determining the grain yield in wheat. Our results showed that the location effect and the interaction effect of location $\times$ year were highly significant for grain number in a SHBW spike $(\mathrm{P}<0.001)$. The highest value for grain number $(86.50)$ was observed in Taian in 2009-2010 whereas the lowest (52.83) was seen in Cangzhou in 2009-2010 (Table 5).

Wheat cultivars often show highly significant genotype by environment interaction $(\mathrm{G} \times \mathrm{E})$ for grain number, even when comparing different years within a relatively stable location (Tarakanovas et al., 2006). Grain formation is a very complicated process and might be influenced by multiple factors. Drought prior to pollination strongly reduced the number of fertile florets and grains, whereas terminal drought reduced the number of grains per spike in spring wheat (Rajala et al., 2009). This could explain that the grain number in Jiyuan was less than that in Taian. However, the lowest grain number among the three growth locations was in Cangzhou, it has reported that salinity decreased grain number on the main stem significantly at maturity in wheat (El-Hendawy et al., 2005). It is worthy of further study if the grain number in Cangzhou was affected by salinity soil. 
Table 5. The grain number within different spike parts for two growing seasons (2008-2010) in Taian, Cangzhou and Jiyuan, Huanghuai Wheat zone, China* ${ }^{*}$. The data units are grain number

\begin{tabular}{|c|c|c|c|c|c|c|c|}
\hline & & \multicolumn{3}{|c|}{ Main rachis } & \multicolumn{3}{|c|}{ Lower part } \\
\hline & & Upper part & Lower part & Whole pike & $\begin{array}{l}\text { Toppest branched } \\
\text { rachises }\end{array}$ & $\begin{array}{l}\text { Middle branched } \\
\text { rachises }\end{array}$ & $\begin{array}{c}\text { Lowest branched } \\
\text { rachises }\end{array}$ \\
\hline \multirow[t]{3}{*}{ 2008-2009 } & Taian & $16.70 \pm 2.31$ & $60.37 \pm 4.64$ & $77.07 \pm 6.35$ & $5.41 \pm 4.31$ & $8.38 \pm 7.23$ & $4.41 \pm 0.33$ \\
\hline & Cangzhou & $12.10 \pm 1.60$ & $40.73 \pm 3.96$ & $52.83 \pm 4.56$ & $5.53 \pm 3.28$ & $6.50 \pm 5.63$ & $1.46 \pm 0.26$ \\
\hline & Jiyuan & $12.26 \pm 0.98$ & $49.07 \pm 3.65$ & $61.33 \pm 7.26$ & $4.43 \pm 4.29$ & $6.51 \pm 5.61$ & $5.60 \pm 0.32$ \\
\hline \multirow[t]{3}{*}{$2009-2010$} & Taian & $21.83 \pm 1.89$ & $64.67 \pm 5.82$ & $86.50 \pm 7.23$ & $6.43 \pm 5.78$ & $10.35 \pm 8.52$ & $6.04 \pm 0.56$ \\
\hline & Cangzhou & $16.77 \pm 2.11$ & $32.57 \pm 2.94$ & $49.33 \pm 5.61$ & $5.54 \pm 3.64$ & $3.97 \pm 4.17$ & $1.92 \pm 0.21$ \\
\hline & Jiyuan & $15.60 \pm 1.32$ & $55.20 \pm 4.63$ & $70.80 \pm 7.32$ & $5.00 \pm 3.98$ & $6.94 \pm 5.76$ & $5.68 \pm 0.48$ \\
\hline
\end{tabular}

*, Upper part indicated that the grain number of the upper main rachises with no branched rachises, and lower part indicated that the grain number of all branched rachises within lower part of the main rachis. Whole spike indicated that all the grain number in the whole spike; toppest branched rachises, middle branched rachises and lowest branched rachises indicated that the average grain number of two branched rachises within the lower part of main rachis; the values were showed as $\mathrm{SD}$.

The results showed that the location effect were highly significant for the mean grain number within the branched rachises $(\mathrm{P}<0.01)$ (Table 5). CVs of grain number within the branched rachises $(36.80 \%)$ were more than those within the upper part of main rachis $(22.59 \%)$ or within the whole spike $(21.73 \%)$. Different with the rachis length and node number, $\mathrm{CV}$ of grain number within the toppest two branched rachises $(12.30 \%)$ was less than those within the middle (29.99\%) or lowest $(48.19 \%)$ two branched rachises, and it seemed that the grain number at the lower branched rachises was more easily affected by the environment.

\subsection{The Weight of Grain within Different Spike Parts}

Our results showed that the grain weight within a whole spike was significantly different under various environments $(\mathrm{P}<0.01)$. The year effect and the interaction effect of location $\times$ year were highly significant for thousand grain weight $(\mathrm{TGW})$ in a spike $(\mathrm{P}<0.001)$ (Table 6). The highest value for TGW $(36.54 \mathrm{~g})$ was observed in Taian in 2009-2010 whereas the lowest (23.96 g) was seen in Jiyuan in 2009-2010 (Table 6).

Table 6. The thousand grain weight (TGW) of grain within different spike parts for two growing seasons (2008-2010) in Taian, Cangzhou and Jiyuan, Huanghuai Wheat zone, China ${ }^{*}$. The data units are gram per thousand grain weight

\begin{tabular}{|c|c|c|c|c|c|c|c|}
\hline & & \multicolumn{3}{|c|}{ Main rachis } & \multicolumn{3}{|c|}{ Lower part } \\
\hline & & Upper part & Lower part & Whole pike & $\begin{array}{c}\text { Toppest branched } \\
\text { rachises }\end{array}$ & $\begin{array}{l}\text { Middle branched } \\
\text { rachises }\end{array}$ & $\begin{array}{l}\text { Lowest branched } \\
\text { rachises }\end{array}$ \\
\hline \multirow[t]{3}{*}{$2008-2009$} & Taian & $37.54 \pm 3.54$ & $27.46 \pm 2.41$ & $30.58 \pm 3.56$ & $32.54 \pm 2.67$ & $28.00 \pm 1.96$ & $27.49 \pm 2.65$ \\
\hline & Cangzhou & $33.31 \pm 2.36$ & $23.26 \pm 1.96$ & $26.59 \pm 1.96$ & $27.70 \pm 3.54$ & $25.60 \pm 1.36$ & $25.25 \pm 2.53$ \\
\hline & Jiyuan & $27.31 \pm 1.96$ & $24.39 \pm 1.85$ & $25.53 \pm 2.69$ & $26.40 \pm 3.12$ & $24.83 \pm 2.45$ & $25.01 \pm 2.64$ \\
\hline \multirow[t]{3}{*}{$2009-2010$} & Taian & $28.14 \pm 3.86$ & $37.11 \pm 2.63$ & $36.54 \pm 4.54$ & $35.24 \pm 2.63$ & $38.54 \pm 2.89$ & $41.35 \pm 3.78$ \\
\hline & Cangzhou & $25.42 \pm 1.97$ & $23.64 \pm 1.96$ & $24.39 \pm 2.35$ & $21.97 \pm 2.36$ & $24.30 \pm 2.47$ & $22.29 \pm 1.36$ \\
\hline & Jiyuan & $25.08 \pm 2.36$ & $23.76 \pm 2.56$ & $23.96 \pm 3.45$ & $26.40 \pm 2.84$ & $24.83 \pm 3.12$ & $25.01 \pm 2.68$ \\
\hline
\end{tabular}

*, Upper part indicated that the TGW of grain within the upper main rachises with no branched rachises, and lower part indicated that the TGW of grain within all branched rachises. Whole spike indicated that TGW of all grain of in the whole spike; toppest branched rachises, middle branched rachises and lowest branched rachises indicated that the TGW of grain within two branched rachises at different positions within the lower part of main rachis; the values were showed as SD.

The grain weight in branched rachises demonstrated similar characteristics under different environments. The year effect and the interaction effect of location $\times$ year were highly significant for TGW $(\mathrm{P}<0.01)$. The CVs of TGW 
within branched rachises (19.45\%) were higher than that of the upper no-branching main rachis $(16.75 \%)$, and also higher than that of the whole spike $(17.32 \%)$.

Except for the toppest branched rachises $(16.80 \%)$, the variance ranges of TGW of grain within the middle and lowest branched rachis were $19.79 \%$ and $24.78 \%$ respectively, which were higher than those of grain within all the spike (17.32\%), or within the upper no branching main rachis $(16.76 \%)$.

Grain weight at maturity is dependent on several factors, drought and increased temperature before the end of grain filling shortened the grain filling period and reduced mean grain weight (Patil et al., 2008; Kaur \& Behl, 2010). The grain weight in Jiyuan was the lowest among the three growth locations, and this might be due to the drought experienced through the reproductive period. Wheat grain maturity processes involved in yield formation and regulation of grain weight are dependent on the availability of carbon (C) and $\mathrm{N}$ assimilates during formation of the grain sink capacity and during grainfilling (Bhardwaj et al., 2010); Physiological mechanisms of grain weight determination has been focused on the period when the grains actually grow (Egli, 1998) and the period immediately preceding anthesis, when the carpels grow, also seems to be important for grain weight (Wardlaw, 1994; Calderini \& Reynolds, 2000). In addition, in normal wheat, the position of grain at the spike had great effects on grain weight or grain number (Slafer et al., 1994; Acreche et al., 2006). In view of grain weight taking a great role on wheat yield, more research is needed on the effects of the external environments or position of grain at a spike on the grain weight in a SHBW line.

\subsection{Variance Characteristics of the Four Spike Characters}

The CVs of the rachis length, the number of rachis node and seed set, and the grain weight within respective spike parts were different among various environments (Table 7). CVs of grain number and grain weight in the whole spike were $19.56 \%$ and $17.32 \%$ respectively, which were much higher than those of main rachis length (9.78\%) and main rachis node $(8.49 \%)$. This indicated that grain number and grain weight were easily changing with external environments, and rachis node number was the least characteristic influenced by the environment. This result was similar with that of previous research in normal wheat. It has been reported that the number of developing florets or grain number in normal wheat was reduced under non-beneficial environments, such as pre-anthesis shading or fusarium infection, and other structural components of the spike (such as rachis length or rachis node) were less influenced (Briceno-Felix et al., 2009; Tonev et al., 2008).

Table 7. Variance characteristics of the four spike morphological characteristics within different spike parts for two growing seasons (2008-2010) in Taian, Cangzhou and Jiyuan, Huanghuai Wheat zone, China*

\begin{tabular}{|c|c|c|c|c|c|c|c|}
\hline & \multicolumn{3}{|c|}{ Main rachis } & \multicolumn{4}{|c|}{ Lower part } \\
\hline & $\begin{array}{l}\text { Upper } \\
\text { part }\end{array}$ & $\begin{array}{c}\text { Lower } \\
\text { part }\end{array}$ & Total & $\begin{array}{c}\text { Toppest branched } \\
\text { rachises }\end{array}$ & $\begin{array}{l}\text { Middle branched } \\
\text { rachises }\end{array}$ & $\begin{array}{l}\text { Lowest branched } \\
\text { rachises }\end{array}$ & Mean \\
\hline Rachis length & 19.15 & 13.14 & 9.78 & 56.19 & 51.00 & 56.92 & 54.45 \\
\hline Rachis node & 20.08 & 7.57 & 8.49 & 36.92 & 28.33 & 34.75 & 37.21 \\
\hline Grain number & 22.59 & 24.11 & 21.73 & 12.30 & 29.99 & 48.19 & 36.80 \\
\hline TGW & 16.76 & 20.18 & 17.32 & 16.80 & 19.79 & 24.78 & 19.45 \\
\hline
\end{tabular}

${ }^{*}$ The value expressed as \%.

Within branched rachises, the CV of average length was $54.45 \%$, which was the maximum amongst the four morphological traits, and this means that the length of branched rachises was easy to be influenced by external environments. The length of main rachis and branched rachises might be controlled by different genetic mechanisms, which resulted to the different sensitivity of rachis length to external environments. The length of branched rachises was positively correlated with the rachis node number $(\mathrm{P}<0.01)$ within all the branched rachises and the grain number within the two toppest branched rachises $(\mathrm{P}<0.05)$. The position of the branched rachis had a great effect on grain number per rachis. As observed in the SHBW spikes in Jiyuan, the length of some branched rachises was very short, and several florets seemed to be clustered together. However, based on pairs of lemma, it could be seen that it was spikelets, not florets, attached at a rachis node. In this kind of spike, although the branched rachises were very short, spikelets clustered together and the grain number reduced less within the lowest two branched rachises and reduced greatly within the middle two branched rachises. The environment may influence 
the node number and grain number per spike, but the length of branched rachises might be one important influencing factor in determining grain yield in a SHBW.

\section{Conclusions}

The present research showed that two spike morphologies displaying in a main rachis is a common characteristic in SHBW under various environments, but the proportion of branching part within the main rachis varied to some extent.

The four morphological characteristics within the main rachis and the branched rachises were both significantly influenced by various environments. But the CVs of these characteristics within the branched rachises were much higher than those within the whole spike or the upper part of the main rachis. This indicated that the traits within branched rachises were more easily influenced by various environments in SHBW.

Among the four spike traits, CV of grain number within the whole spike was the most. Within the branched rachises, the variation in average length was the highest. More long branched rachises might be beneficial for grain set.

In order to make full utilization of this kind of wheat, more attention should be paid to choose breeding lines with relatively stable branched rachises traits, at mean time, more grain and longer branched rachises in these lines should also be regarded as two important choice factors in SHBW future breeding process.

To our knowledge, this is the first study to describe the influence of external environments on the spike morphology in SHBW. The research might provide useful information for SHBW breeding in the future.

\section{Acknowledgements}

Many thanks to our Wheat Breeding Team, including Bi Jianjie, Cailing Sun, Yongxiang Zhang, and Xiansheng Chen at the Agronomy College, Shandong Agriculture University.

\section{References}

Acreche, M. M., Slafer, A., \& Gustavo, G. (2006). Grain weight response to increases in number of grains in wheat in a Mediterranean area. Field Crop Res., 98, 52-59. http://dx.doi.org/10.1016/j.fcr.2005.12.005

Bhardwaj, V., Yadav, V., \& Chauhan, B. S. (2010). Effect of nitrogen application timings and varieties on growth and yield of wheat grown on raised beds. Arch Agro Soil Sci., 56(2), 211-222. http://dx.doi.org/10.1080/03650340903092218

Briceno-Felix, G., Sanchez, J. A. M., Slafer, G. A., \& Acreche, M. M. (2009). Grain number determination in an old and a modern Mediterranean wheat as affected by pre-anthesis shading. Crop Pastu Sci., 60(3), 271-279. http://dx.doi.org/10.1071/CP08236

Calderini, D. F., \& Reynolds, M. P. (2000). Changes in grain weight as a consequence of de-graining treatments at pre- and postanthesis in synthetic hexaploid lines of wheat (Triticum durum $\times T$. tauschii). Aust. J. Plant Physiol, 27, 183-191. http://dx.doi.org/10.1071/PP99066

Dencic, S. (1988). Genetic analysis of different structures of sink capacity in wheat. In Proc. 7th Intern (pp. 499-502). Wheat Genet. Symp. Cambridge, UK.

Egli, D. B. (1998). Seed growth and development. In Egli DB (Eds.). Seed biology and the yield of grain crops (pp. 120-128). New York, USA: CAB International.

El-Hendawy, S. E., Hu, Y., Yakout, M., Ahmed, A. M. G., Salah, H. E., \& Schmidhalter, U. (2005). Evaluating salt tolerance of wheat genotypes using multiple parameters. Eur. J. Agrono, 22(3), 243-253. http://dx.doi.org/10.1016/j.eja.2004.03.002

Ghodsi, M. (2004). Ecophysiological aspects of water deficit on growth and development of wheat cultivars. PhD. Thesis. University of Tehran, Iran.

Huang, G., \& Yen, C. (1988). Studies on the developmental genetics of multiple spikelet per spike in wheat. In Proc. 7th Intern (pp. 527-532). Wheat Genet Symp, Cambridge, UK.

Hussain, M. M., Ibrahim, S., \& Zaitoon, A. (1984). Effect of nitrogen levels on the growth, yield and mineral composition of wheat crop under different seed rates. Egypt J. Sci., 24(1), 7-18.

Iqbal, M., Ahmad, K. I., Sadiq, M., \& Ashraf, M. Y. (1999). Yield and yield components of durum wheat as influenced by water stress at various growth stages. Pak. J. Biol Sci., 2, 1438-1440. 
Jan, A., Khan, M. Y., Marwat, M. I., \& Muhammad, T. (2000). Impact of intra-specific competition on the agronomic traits of wheat. Pak. J. Bio Sci, 3(12), 2016-2019.

Kaur, V., \& Behl, R. K. (2010). Grain yield in wheat as affected by short periods of high temperature, drought and their Interaction during pre- and post-anthesis. Cereal Research Communications, 38(4), 514-520. http://dx.doi.org/10.1556/CRC.38.2010.4.8

Koric, S. (1975). Genetic basis for high spike productivity. In Proceedings of the 2nd Intern Winter wheat Conference, Zagreb, Yugoslavia (pp.188-144). U.S. Department of Agriculture.

Koric, S. (1980). Study of branched gene complex of Triticum aestivum ssp. vulgare and its significance for wheat breeding. J. Sci. Agric. Res. Zagreb Yugoslavia, 142, 271-282.

Patil, R. V., Chinnusamy, V., Chauhan, S., Ruwali, K. N., Pandey, H. N., \& Khanna-Chopra, R. (2008). Evaluation of heat stress tolerance in T. aestivum and T. durum wheat genotypes under continual and terminal heat stress environments. J, Plant Bio., 35, 1-16. http://dx.doi.org/10.1023/A:1003531722420

Peanell, A. L., \& Halloran, G. M. (1983). Inheritance of supernumerary spikelet development in wheat. Euphytca, $32,767-776$.

Peng, Z. S., Yen, C., \& Yang, J. L. (1998). Chromosomal location of genes for supernumerary spikelet in breed wheat. Euphytica, 103, 109-114. http://dx.doi.org/ 10.1023/A:1018323310621

Rajala, A., Kaija, H., Pirjo, M. T., Susanna, M., \& Peltonen-Sainio, P. (2009). Spring wheat response to timing of water deficit through sink and grain filling capacity. Field Crop Res., 114(2), 263-271. http://dx.doi.org/10.1016/j.fcr.2009.08.007

Rizwan, A. S., Shahzad, M. K., Arshad, A. M., \& Mahmood, M. H. (2007). Growth and yield response of wheat and maize to nitrogen and L. tryptophan enriched compost. Pak. J. Bio. Sci., 39(2), 541-549.

Sharman, B. C. (1967). Interpretation of the morphology of various naturally occurring abnormalities of the influorescence of wheat (Triticum ssp.). Cana. J. Bot., 45, 2073-2080. http://dx.doi.org/ 10.1139/b67-224

Slafer, A., Gustavo, D., \& Roxana, S. (1994). Source-sink relationships and grain mass at different positions within the spike in wheat. Field Crop Res., 37, 39-49. http://dx.doi.org/ 10.1016/0378-4290(94)90080-9

Sun, D. F., Zhu, X. D., Wan, Z. B., \& Cai, J. (2000). The stability and expression in F1 generation of supernumerary spikelets in bread wheat. Journal of Huazhong Agricultural University, 19, 213-218.

Tarakanovas, P., \& Ruzgas, V. (2006). Additive main effect and multiplicative interaction analysis of grain yield of wheat varieties in Lithuania. Agro. Res., 4(1), 91-98.

Tonev, T. K., Kiryakova, V., \& Milev, G. (2008). Influence of some agronomy factors on spike components after a rare incidence of fusarium head blight epiphytoty of winter wheat I. Effect of long-term crop rotation, mineral fertilization and sowing term. Bulgarian journal of agricultural science, 14(3), 321-328.

Tschermak, von E. (1914). Uber die Vererbungsweise von Art und Gattungsbastarde innerhalb der Getreidegruppe. Mitteil. Der landw. Lehrkanzeln der KK Hochschule für Bodenkultur in Wien Bd. (ii) Heft

Wardlaw, I. F. (1994). The effect of high temperature on kernel development in wheat: variability related to pre-heading and post-anthesis conditions. Aust. J. Plant Physiol. 21, 731-739. http://dx.doi.org/10.1071/PP9940731

Yuan, W. Y., Sun, Y., Chang, M. R., Pei, Z. Y., \& Sun, S. C. (1995). Genetics study on common wheat with branched spike transferred from Triticum turgidum Compositum. Acta Agriculturae Boreali-Sinica, 10(3), 45-50.

Zhao, P., Peng, H. R., Ni, Z. F., Lu, L. H., Wang, J., \& Sun, Q. X. (2009). Heterosis and combining ability of major agronomic traits in crosses between ear-branched wheat and common wheat. Journal of Triticeae Crops, 29(2), 212-216. 